\title{
FAILURE OF SPERM SEDIMENTATION TO INFLUENCE THE SEX RATIO OF RABBITS
}

\author{
J. M. BEDFORD AND ANNE-MARIE BIBEAU \\ The Worcester Foundation for Experimental Biology, \\ Shrewsbury, Massachusetts
}

(Received 3rd March 1967)

Recently there has been a resurgence of interest in the possibility of separating $X$ and Y spermatozoa, following reports by Bhattacharya $(1958,1962)$ that when cooled to immobility in media of certain viscosity, $\mathrm{X}$ spermatozoa of rabbits appear to sediment at a relatively faster rate than $\mathrm{Y}$ spermatozoa. Using this principle with a modified medium, Schilling (1966) reported births in cattle which showed a deviation of the sex ratio, but a similar study in cattle failed to achieve any such deviation (Bhattacharya, Bangham, Cro, Keynes \& Rowson, 1966).

The present communication reports the results of experiments in rabbits to test the hypothesis that spermatozoa will tend to separate into distinct populations ( $\mathrm{X}$ and $\mathrm{Y}$ ) during passive sedimentation in a defined medium.

The apparatus and medium used were essentially those developed and shown to one of us (J.M.B.) by Dr E. Schilling. The medium was made as follows: $7.6 \mathrm{~g}$ powdered milk were dissolved in $64 \mathrm{ml}$ distilled $\mathrm{H}_{2} \mathrm{O}$; this solution was heated to $90^{\circ} \mathrm{C}$ for $10 \mathrm{~min}$ and filtered; $13 \mathrm{ml}$ of glucose $(3.75 \%), 13 \mathrm{ml}$ of sodium citrate $(2.9 \%), 18.5 \mathrm{~g}$ egg yolk, $1 \mathrm{ml}$ warmed gelatin $(10 \%)$ and $2 \mathrm{ml}$ $\mathrm{H}_{2} \mathrm{O}$ containing $0.5 \mathrm{mg}$ penicillin and $0.5 \mathrm{mg}$ streptomycin were then mixed with the milk solution. Rabbit semen of good motility was collected from fertile males with an artificial vagina, and the sperm concentration estimated with a haemocytometer. Pooled semen was then centrifuged for $10 \mathrm{~min}$ at 3000 $\mathrm{rev} / \mathrm{min}$, following which the spermatozoa were resuspended in the sedimentation medium at a concentration usually of about 200 to $300 \times 10^{6} / \mathrm{ml}$. This sperm suspension was cooled to immobility in an insulated jacket, at $2^{\circ} \mathrm{C}$ during $2 \mathrm{hr}$. One $\mathrm{ml}$ of the suspension was then layered carefully in a modified burette on top of a column of $19 \mathrm{ml}$ of the same medium, previously cooled to $2^{\circ} \mathrm{C}$. Initially, the spermatozoa were allowed to sediment for $2 \mathrm{hr}$ at $2^{\circ} \mathrm{C}$. Twenty fractions, each of $1 \mathrm{ml}$, were then recovered from the column and the number of spermatozoa in each fraction was estimated. The sperm distribution profile in each of eight experiments is shown in Text-fig. 1. Depending on the numbers of spermatozoa present, the lowest 2 to 5 fractions were used for insemination. These fractions were pooled and centrifuged for $4 \mathrm{~min}$ at 3000 $\mathrm{rev} / \mathrm{min}$, following which the concentrated spermatozoa were inseminated 


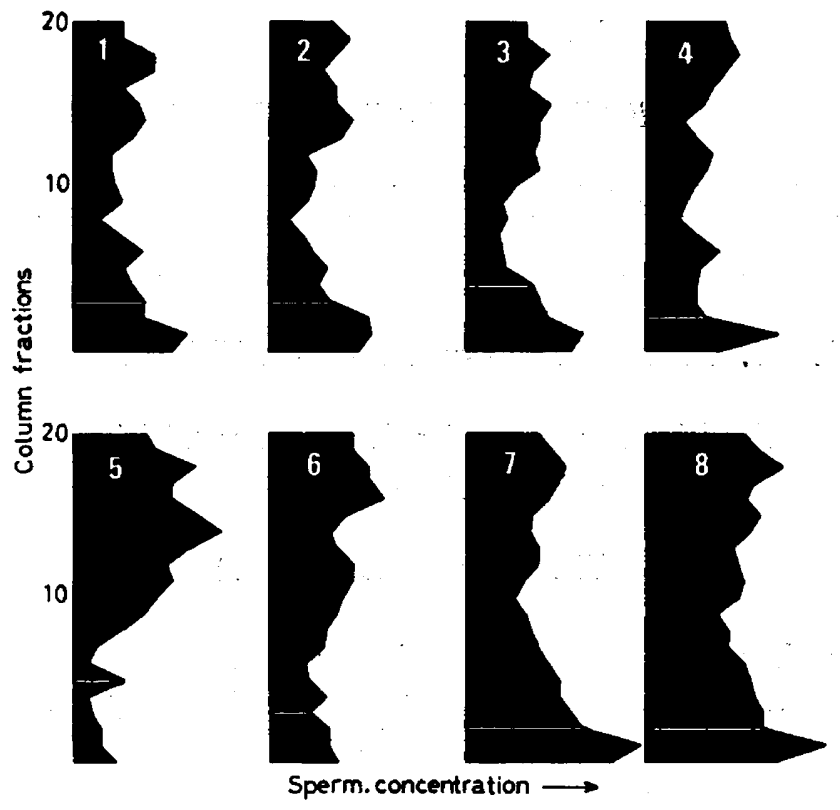

Text-Fig. 1. Distribution of profiles of spermatozoa samples after $2 \mathrm{hr}$ sedimentation (experimental series 1). Inseminations were performed with fractions lying below the white line.

intra-vaginally in $0.5 \mathrm{ml}$ into an oestrous female, which was then given an ovulating injection of 90 i.u. HcG. The inseminated females were killed 26 to 28 days later, the corpora lutea and implantation sites counted, and the gonads of any foetuses examined histologically.

TABLE 1

SEX OF FOETUSES FROM FEMALES INSEMINATED WITH LOWER FRACTIONS RECOVERED AFTER 2-hr SEDIMENTATION

\begin{tabular}{|c|c|c|c|c|}
\hline \multirow{2}{*}{$\begin{array}{l}\text { No. sperm. } \\
\text { deposited } \\
\text { initially } \\
\text { (millions) }\end{array}$} & \multirow{2}{*}{$\begin{array}{c}\text { Column } \\
\text { fractions } \\
\text { inseminated }\end{array}$} & \multicolumn{2}{|c|}{ Sex of foetuses } & \multirow{2}{*}{$\begin{array}{l}\text { No. } \\
\text { foetuses } \\
\text { resorbed }\end{array}$} \\
\hline & & Male & Female & \\
\hline $\begin{array}{l}190 \\
232 \\
208 \\
200 \\
212 \\
216 \\
312 \\
772\end{array}$ & $\begin{array}{l}1-3 \\
1-3 \\
1-4 \\
1-2 \\
1-5 \\
1-3 \\
1-2 \\
1-2\end{array}$ & $\begin{array}{l}7 \\
6 \\
7 \\
5 \\
\text { Not } \\
6 \\
2 \\
2\end{array}$ & $\begin{array}{r}4 \\
1 \\
9 \\
2 \\
\text { nant } \\
7 \\
1 \\
3\end{array}$ & $\begin{array}{l}2 \\
2 \\
1 \\
- \\
- \\
- \\
-\end{array}$ \\
\hline Total & & 35 & 27 & 5 \\
\hline
\end{tabular}

Density of medium at $2^{\circ} \mathrm{C}=1 \cdot 048$. Viscosity of medium at $2^{\circ} \mathrm{C}=6.7 \mathrm{cP}$.

In a further six experiments, the same procedure was used except that two sedimentation columns were used on each occasion, and the spermatozoa in both the two top and the two bottom fractions, respectively, were inseminated. 


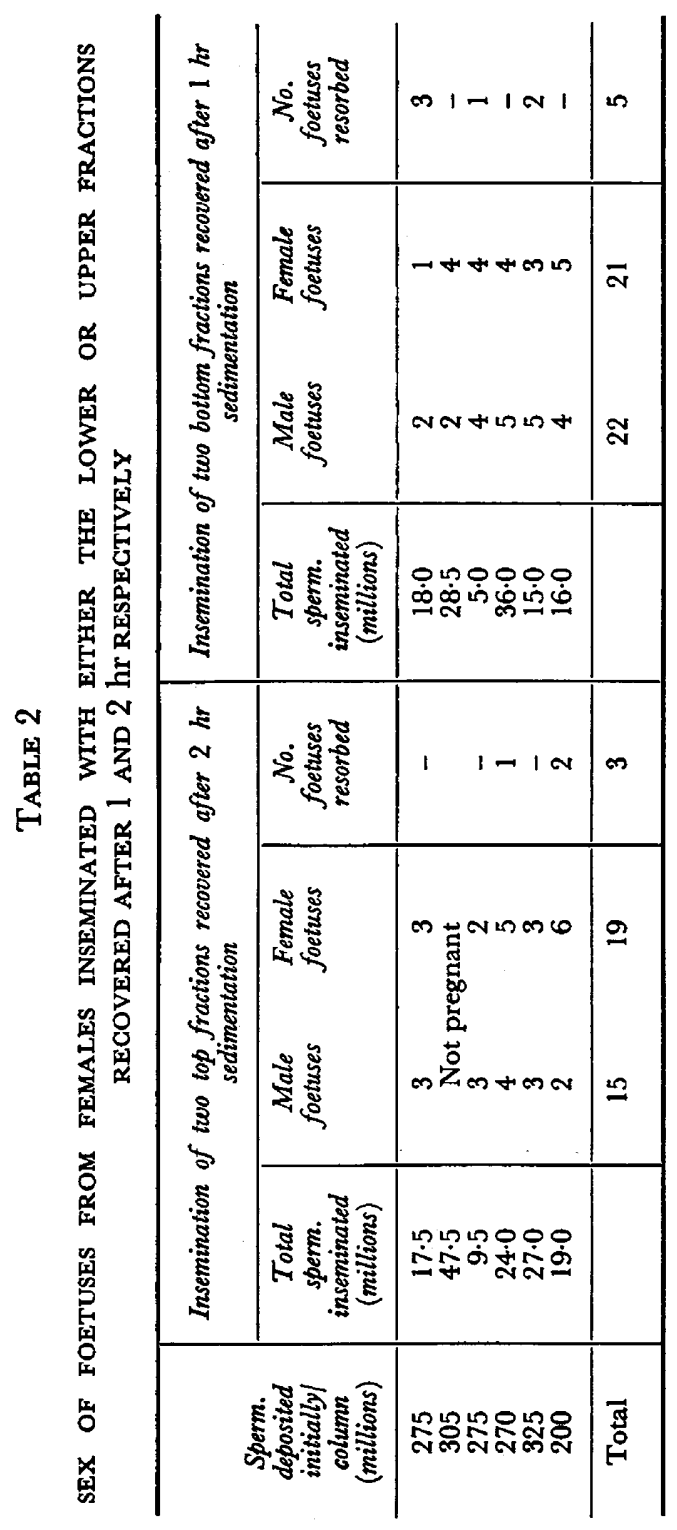


The two lowest fractions were recovered from both columns after only $1 \mathrm{hr}$, whereas the two top fractions were collected after a total of $2 \mathrm{hr}$ sedimentation. After 28 days the corpora lutea were counted, and the sex of the foetuses was assessed macroscopically.

The results obtained in both experimental series (Tables 1 and 2) gave no indication that $\mathrm{X}$ and $\mathrm{Y}$ spermatozoa of rabbits may be separated by sedimentation. In the first series there was, in one or two cases, some indication of a bimodal sperm distribution (see Text-fig. 1), but no consistent sedimentation pattern of the uni-modal type mentioned by Schilling (1966) was obtained. Nevertheless, a considerable degree of vertical separation occurred during the 2-hr sedimentation period, such that the lower fractions used for insemination never contained more than $15 \%$ of the total spermatozoa deposited onto the column. Seven of the eight animals inseminated became pregnant (average litter size: $8 \cdot 8$ ), but no litter contained a preponderance of females; overall, with spermatozoa recovered in the bottom fractions, rather more males (thirtyfive) than females (twenty-seven) were conceived (Table 1).

In the second series of experiments, although the procedure was weighted in favour of the original hypothesis, in no instance was there any significant deviation of the sex ratio in the expected direction (Table 2). Of six females inseminated with spermatozoa from the top two fractions, five became pregnant (average litter size: 6.8), but against expectation more females (nineteen) than males (fifteen) were conceived. Insemination with the two 'heaviest' fractions from the same columns resulted in all of six females becoming pregnant (average litter size: $7 \cdot 2$ ), but again no significant deviation of the sex ratio was found.

Although rabbit spermatozoa will sediment at differential rates in a viscous medium of the type used here, this separation does not appear to correspond with the sex chromosome complement of the spermatozoa. It is concluded that, in rabbits at least, this type of sedimentation technique is unlikely to afford a means of controlling the sex ratio of progeny.

This work was supported by National Institutes of Health Grant No. GM10529 awarded to Dr M. C. Chang.

\section{REFERENCES}

Bhattacharya, B. Ch. (1958) Sex control in mammals. Z. Tierzücht. ZüchtBiol. 72, 250.

Bhattacharya, B. Ch. (1962) Die verschiedene Sedimentationsgeschwindikeit der X und Y Spermien und die Frage der wilkürliehen Geschlechtsbestimmung. Z. wiss. Zool. 166, 203.

Bhattacharya, B. Ch., Bangham, A. D., Cro, R. J., Keynes, R. D. \& Rowson, L. E. A. (1966) An attempt to predetermine the sex of calves by artificial insemination with spermatozoa separated by sedimentation. Nature, Lond. 211, 863.

Schilling, E. (1966) Experiments in sedimentation and centrifugation of bull spermatozoa and the sex ratio of born calves. F. Reprod. Fert. 11, 469 . 